\title{
Culture Shock and Job Expectations Adjustment among Nigerian Self-Initiated Expatriates in the United Kingdom
}

\author{
Oluwadare, Sunday Victor \\ School of Business and Law, University of East London, London, United Kingdom
}

Received: Nov. 5, 2018 Accepted: Dec. 29, 2018 Online published: Jan. 15, 2019

doi:10.5296/ijhrs.v9i1.13865 URL: https://doi.org/10.5296/ijhrs.v9i1.13865

\begin{abstract}
Purpose: A great number of people in the world today, live and work outside the shores of their nations of origin. It is imperative to investigate how they are faring in the face of job satisfaction/dissatisfaction and the divergent cultural environment of their sojourn in order to correctly harness their inter-cultural usefulness across the globe. This research investigated the factors that influenced the relocation of Nigerians to the United Kingdom and sustained them there, in spite of their job experiences and culture shock.

Methodology/Approach: Methodology triangulation of both questionnaire survey on seventy-six participants and six in-depth interviews was employed. Reflexivity, thick description and grounded theory were the approaches engaged in the data analysis and Interpretation of results.

Findings: The findings revealed that multiple reasons like education, economic, socio-political and personal, are 'pushing' Nigerians from home and 'pulling' them to the United Kingdom. It was also discovered that the Nigerians in the United Kingdom, are experiencing different forms of job dissatisfaction and culture shock but for some salient reasons, they adjust fairly well to the environment.
\end{abstract}

Keywords: Self-initiated expatriates, job expectations, culture shock, and socio-cultural adjustment.

\section{Introduction}

Getting necessary and capable talents from local labour markets, has become difficult if not impossible, hence the increase demand for talents from the global labour market. De Haas (2005) argued that the trend does not benefit only the organisations as employers of these emigrants but both governments and organisations at various levels and nations are maximising these opportunities. 
Subsequently, the need for expatriation became prominent but researches (Harzing \& Pinnington, 2011) are indicating that the process is quite costly and the rate, at which foreign assignments fail, is quite disturbing. Selmer (2001) estimated foreign assignment's cost to be between three and five times the assignee's home salary. Summarily, expatriation is expensive. Scholars like Welch et al., (2007), and Harzing \& Pinnington (2011), have suggested copious measures toward reducing the cost of expatriation and curbing its failure. In the words of Al Ariss (2010), using the self-initiated expatriates (SIEs) on foreign assignments, is a good option in resolving the problems of expatriation. The SIEs are a very viable human resource around the world but they are, unfortunately, being neglected (Welch et al., 2007). Among these are Nigerians who travel to the United Kingdom, to live, study and work (Al Ariss \& Özbilgin, 2010). The Organisation for Economic Co-operation and Development (OECD) in 2013, puts the inflow of Nigerians to the UK at 10,000 on the average between 2006 and 2011 and the stock of Nigerian population in the UK by 2011 is 114,000 . In spite of the divergent socio-cultural situations of the two nations, Nigerians in the United Kingdom are successful in their chosen careers and economic endeavours. This study therefore aims at examining how these self-initiated expatriates are managing the two divergent socio-cultural environments and in particular, the subtle racism in terms of job dissatisfaction.

\section{Literature Review}

\subsection{Culture Shock and Job Expectations}

Befus (1988) cited in Edwards \& Rees (2011:175) describes culture shock as: "an adjustment reaction syndrome caused by cumulative, multiple, and interactive stress in the intellectual, behavioural, emotional and physiological levels of a person recently relocated to an unfamiliar culture, and is characterised by a variety of symptoms of psychological shock". Culture shock is precipitated by the anxiety one expresses when he/she is losing the life experiences which he/she is conversant and familiar with, for another type which is strange to $\mathrm{him} / \mathrm{her}$. Such cues and symbols of social interaction include when and how to shake hands; what to say and how to say it; when and how to give tips or give orders to servants; when, where and how to shop; when, how and why accept or reject invitations; when to take situation or comment serious or not. Oberg (1960) cited by Kingston \& Forland (2008) also indicated that such cues may come by word, facial expressions, body language and gestures. No matter how broadminded or prepared a person may be, exposure to a new culture would usually have some effects on him/her, which can generate a feeling of frustration and anxiety (Briscoe et al., 2012).

According to Ward and Kennedy (1992), there are four stages of emotional and behavioural reactions/adaptation to the host nation's environment (See Figure 1). First is the honeymoon stage which describes the expat's short visit or early days of his/her stay. At this stage, he/she may not evidently express any anxiety as a result of culture shock just because the visit and interaction with the foreign nation and culture is still short. 


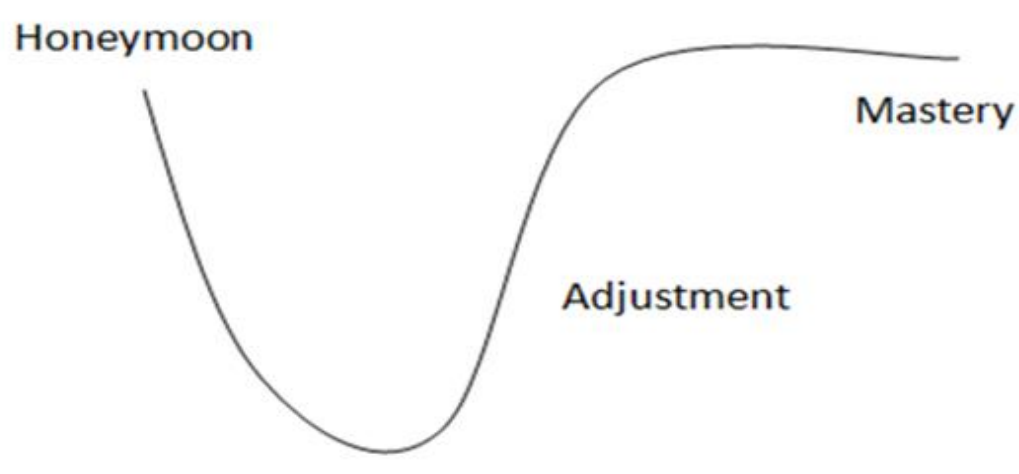

Culture shock

Figure 1. The U-Curve of Cross-cultural Adjustment. Adapted from Black \& Mendenhall (1991:227)

To a migrant whose stay in the host nation is considerably longer, his/her days of being pampered and petted would soon be over (Sims \& Schraeder, 2004). Haslberger (2008) had criticised the description of this stage as 'The honeymoon' stage by submitting that the early period of the expatriate's foreign assignment, is actually the most stressful period. The second stage according to Oberg (2006), is the culture shock stage. At this stage, the expatriate begins to face with maid trouble, school trouble, language trouble, transport trouble, house trouble, shopping trouble and the fact that the host nationals are just indifferent to these troubles, will add to his/her pain (Kingston \& Forland, 2008). He/she therefore gets more aggressive with the view that the people are insensitive and unsympathetic. While reacting to the frustration, he/she begins stereotyping by taking refuge in the colony of his/her home country and begins to tag and name the host nationals derogatorily. This is a very crucial stage that can send the expatriate back home if he/she is not able to overcome the anxiety because it is the stage where verbal and physical clashes with the host nationals and institutional system, are apparent.

The third stage, adjustment, is the stage at which the expatriate begins to gain some knowledge of the host national's language and begins to fumble with it; joke with the host nationals and grow more humorous and make more friends among the host nationals; and is open to learn new things about the culture. At this adjustment stage, the migrant is on the way to recovery. This is the stage where he/she forms or identifies some 'buddy' or 'buddies' from among the host nationals or other foreigners who have been on ground before him/her. Through the buddy, he/she initiates interactions with the wider society and also interprets their actions, reactions and inactions (Black \& Stephen, 1989). However, Nankervis et al., (1993) and Marecek et al., (1997) separately argued that other extrinsic factors like the relationship of the spouse and dependants with the local nationals may facilitate adjustment to the new reality.

At the fourth, mastery or mastering stage, the migrant now accepts the customs of the host nation as just another way of life that is of a great value to the people the same way his/her 
home nation's culture is to his/her own people too. He/she starts to enjoy what they enjoy and dislike what they dislike. He/she gets familiar and comfortable with the host nation's foods, drinks, habits and attitudes to the extent that when he/she returns home, he/she is proud to take such along with him/her and his/her return home will even make him/her generally miss the people and the custom which he/she has eventually been accustomed to. Black \& Stephen, (1989) argued that adjustment rate and manner vary from person to person and over time, against the straight jacketed adjustment stages propounded by Oberg (1960). Bhaskar-Shrinivas et al., (2005) in their research relating the effect of other factors around the expatriates and the length of his/her stay in the foreign nation, affirmed the U-Curve adjustment but with slight modification that makes it appear like a sideways " $\mathrm{S}$ ".

In the words of (Healy \& Oikelome, 2007), job expectations can be described as the anticipated job type, rewards and benefits that an employee estimates as suitable for his/her level of knowledge and skill. Having gone through some training and been certified, one tends to expect some regards while being considered for job placement. Any consideration that falls short of such expectations can lead to job dissatisfaction. The type of job and the benefits attached to it are strong factors that influence culture shock and its adjustment among SIEs (Bhaskar-Shrinivas et al., 2005). An employee can be relatively satisfied with the monetary rewards he/she gets from a job but still be dissatisfied by the way his/her colleagues relate with him/her at work and other aspects of his/her job (Jaime, 2005). Once a migrant perceives that he/she is being treated as a second-class citizen at work, every other interaction with the host nation would be negatively affected. Such migrant begins to presume that all is not well with him/her in such nation (Berry 1997).

\subsection{Motivating Nigerian SIEs in the United Kingdom}

The factors that motivate migrants to relocate and keep them through the whole process through repatriation, vary from the Organisation Expatriates (OEs) to the SIEs (Stroh, et al., 1998). Lewin's 'push-pull' theory is a very relevant model in looking into the factors that propel migration to foreign nations. According to Altman \& Baruch (2013), the theory was propounded to reflect how people are faced with conflicting factors while considering relocation from their home countries to a foreign one. These factors were categorised into two: 'push' and 'pull'.

Mirroring the Nigerians in the UK by the expanded push/pull model by Altman \& Baruch (2013) in Figure 2., there are both intrinsic and extrinsic factors that could have pushed them from Nigeria to the UK. Altman \& Baruch (2013) however argued that the decision to migrate lies mainly within the person. Such values, beliefs, needs and aspirations push the students and the skilled labour out of Nigeria. Working conditions (organisational strategy, policies and practices) especially for those who were working in Nigeria before relocating, are pushing factors also (Healy \& Oikelome, 2007). The historical and contemporary context of political unrest, organizational inequity, social insecurity and injustice are identified as some major environmental pushing factors in Nigeria (Stilwell et al., 2004 and Healy \& Oikelome, 2007). 


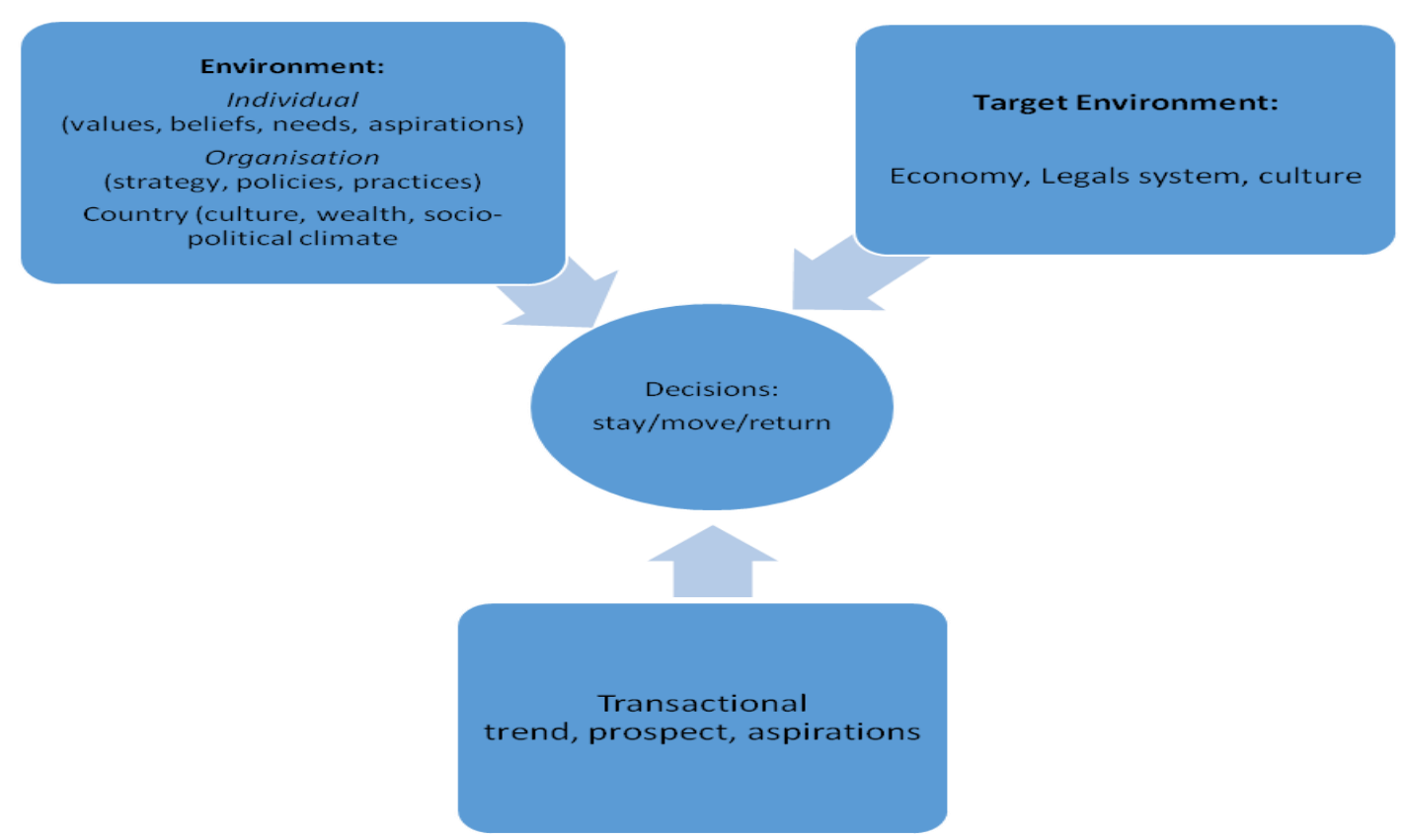

Figure 2. Expanded Push/Pull Model (Adapted by Altman \& Baruch, 2013:24)

The socio-economic factors of the target environment (UK) are the pulling factors. However, the economy, culture, infrastructure, legal system and socio-political climate which pull the migrants, do not seem to sustain their interest (Healy \& Oikelome, 2007). Vujicic et al., (2004), Healy \& Oikelome, (2007) and Imoagene (2012) have submitted separately that Nigerians skilled migrants get nauseated by the covert career glass-ceiling, racial inequality mostly by labour employers, red-tapism, and nepotism in the UK and the pulling factors lose their grips on them. Culture therefore can 'push' or 'pull' any SIE to leave or return home. Schütter \& Boerner (2013) had submitted that some SIEs are actually homesick and some love to trip home regularly. The third field encompasses the influence of personal aspiration, ambition and desire of the SIEs in their career in relation to how living and working in the foreign land, can assist in actualising them. These factors in the context of this study, can reveal how the SIEs' career, personal and social aspiration or ambition, influence their stay in the UK in spite of the culture shock experience.

\section{Methodology}

Considering the nature of this particular study and its specific objectives, the research adopted the pragmatic approach and made use of methodology triangulation of both the quantitative and qualitative techniques. The quantitative method through the use of demographic questionnaires was employed in this research. The questionnaires were administered among the samples that could not have been physically accessed for interview. Also, the method was chosen for its feature of helping to reduce the incidence of intimidation or guided response during interview. It also helped in validating the interview outcomes through proper comparison. The method helped in accessing the resemblance between the responses of the interviewees and those that came in through the questionnaires. The easy and 
seemingly effortless access to the internet by both the researchers and the respondents also informed the use of questionnaires. The questionnaires were designed on Typeform ${ }^{\mathrm{TM}}$ online survey platform and the universal resource locator (url), was sent to the respondents' e-mail addresses and facebook timelines. Some printed copies were also administered on some respondents who preferred such to the online format. Their responses were later entered meticulously into the online database for uniform automatic analysis. The qualitative method was also employed in form of in-depth interviews with some selected samples of the population that could be accessed for such purpose. This method was appropriate because it enabled us to find out directly how they were faring in the face of the divergent cultures of their home and host countries. Coming from a 'high context' country, the interviewees' body language and other non-verbal expression were also easily captured by this method. The method also gave room for possible options or factors that were not originally incorporated in the questionnaires. Using this mixed method had actually helped the study because one method really catered for the limitations and shortcomings of the other.

\subsection{Analysis}

The one hundred participants so selected for the survey were those living within London and could be accessed either physically, via telephones, electronic mails or on the social media. After being contacted and their consents were obtained, sixty (60) of the participants were sent the universal resource locator (url) to the Typeform ${ }^{\text {TM }}$ online survey platform where they were able to complete the survey in approximately ten (10) minutes each. The remaining forty (40) who opted for the hard copy were also served at their agreed rendezvous. After a couple of reminder within the eight weeks with which the survey was out, 32 out of the 40 hard copies of the questionnaires were validly returned and 44 responses came in through the online means. The responses in the paper copies were carefully uploaded to the online platform so that the analysis could be done automatically by the computer system. By the time the online platform was closed, seventy-six (76) responses were available on the platform and such were used for the analysis. Ten participants were contacted for the in-depth interview but after series of efforts to secure comfortable meeting time, only six were eventually interviewed within the available time frame for the research. The audio interviews which took about 18 minutes each, were transcribed and the information obtained really shed light on the culture shock and job satisfaction phenomena among the participants. It also took care of the shortcomings of the survey in achieving the objectives of the study.

\section{Findings}

\subsection{Analysis of the Questionnaire Survey}

Though some of the participants did not answer all the questions, the information accessed through the survey, was helpful in obtaining first hand responses which are essential in viewing the experiences of the Nigerian self-initiated expatriates in the UK to their host nation's socio-cultural environment. 


\section{Macrothink}

International Journal of Human Resource Studies

ISSN 2162-3058 2019, Vol. 9, No. 1

Table 1. Demographics of the Questionnaires' Respondents

\begin{tabular}{|c|c|}
\hline Tools & Respondents \\
\hline Age & 23 (21-30yrs); 29 (31-40yrs); 13: (41-50 yrs); 11: (51 and older) \\
\hline Gender & 41 Female; 35 Male \\
\hline Religion & 1 Muslims; 75 Christians \\
\hline Type of Occupation & $\begin{array}{l}30 \text { Full-time employment; } 10 \text { Part-time employment; } 6 \text { Self-employment; } \\
29 \text { Full-time students }\end{array}$ \\
\hline Highest Education Level & $\begin{array}{l}7 \text { Diploma and below; } 37 \text { Bachelor degree/equivalents; } 28 \text { Master } \\
\text { degree/equivalents; } 2 \text { PhD and higher }\end{array}$ \\
\hline Marital Status & 30 Single; 43 Married; 2 Divorced/Separated \\
\hline $\begin{array}{l}\text { No. of Direct Dependants in } \\
\text { Nigeria }\end{array}$ & 5(1); $15(2) ; 7(3) ; 7$ (4) 14 (more than 4) \\
\hline $\begin{array}{l}\text { No. of Direct Dependants in the } \\
\text { UK }\end{array}$ & 6(1); $13(2) ; 12$ (3); 12 (4) 3 (more than 4) \\
\hline Length of Stay in the UK so far & $\begin{array}{l}9 \text { (less than } 1 \text { yr); } 18(1-2 \text { yrs); } 7 \text { (3-4 yrs); } 15 \text { (5-10 yrs); } 27 \text { (more than } 10 \\
\text { yrs) }\end{array}$ \\
\hline
\end{tabular}

The reasons for the emigration of the participants from Nigeria and their choice of the UK were investigated. The responses are indicated in Figures 3, 4 and 5. The results show that $29(38 \%)$ relocated to the UK for educational reasons (to study or further their studies) while $6(8 \%)$ came on economic ground (to seek better income and life standard). Family influence and other personal reasons pushed 11(14\%) of them out of Nigeria while 28(37\%) had more than one reasons for relocating. To this last category, 23 out of the 28 that indicated 'other' (more than one reason), actually indicated the reasons in order of priority. As shown in Figure 5, educational, economic and personal reasons were paramount to $13(57 \%), 7(30 \%)$ and $3(13 \%)$ of them in that order. 


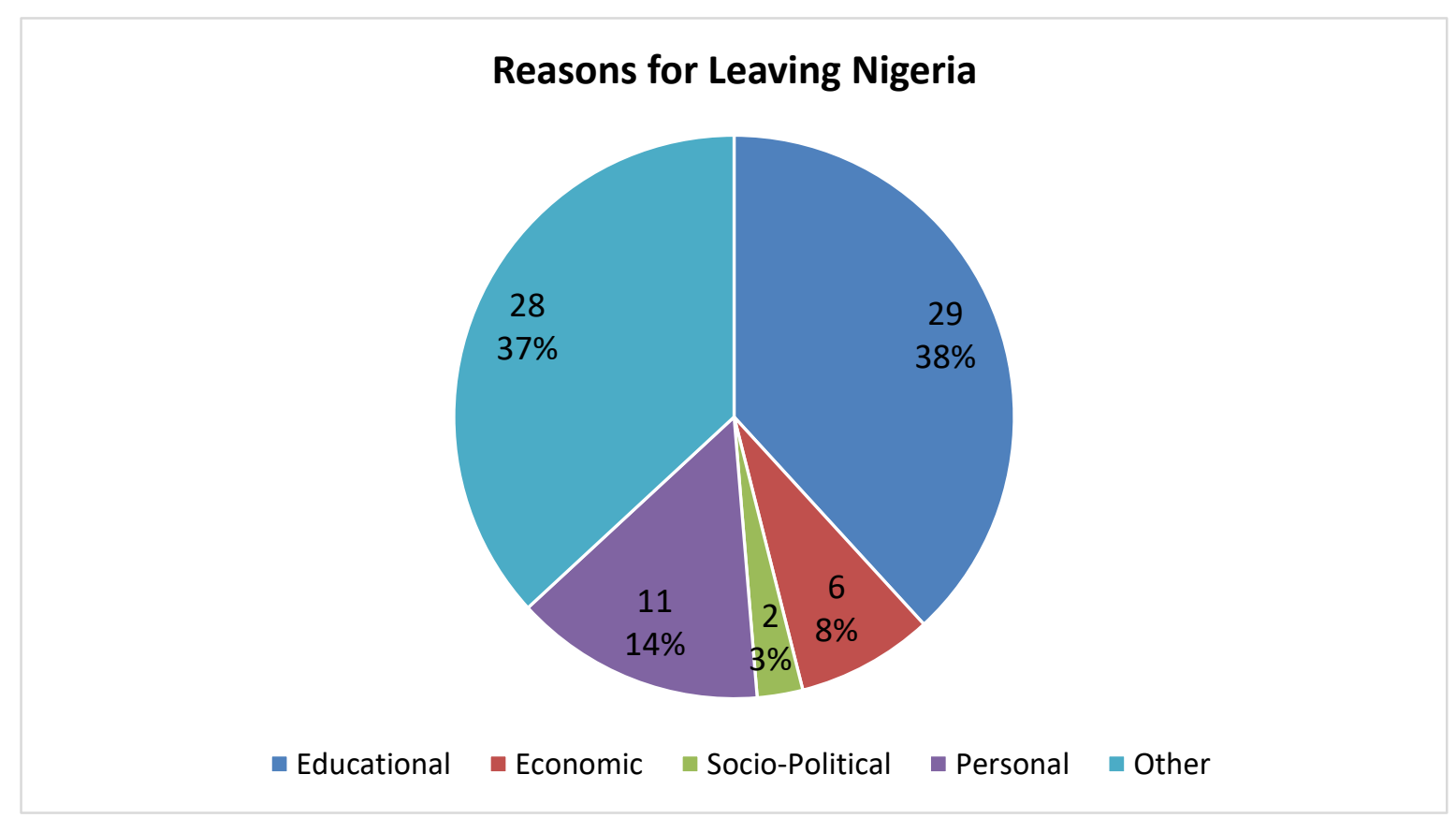

Figure 3. Reasons for Leaving Nigeria

Figure 4 shows that $25(33 \%)$ of the respondents stayed in the UK for educational reasons, $8(11 \%)$ for economic reasons and $17(22 \%)$ for personal reasons. The remaining $26(34 \%)$ indicated that they stayed in the UK for more than one reason and Figure 5 also reveals that economic, education and personal reasons were paramount to $15(58 \%), 6(23 \%)$ and $3(12 \%)$ of them in that order. The remaining 2 did not indicate the order of priority in their responses.

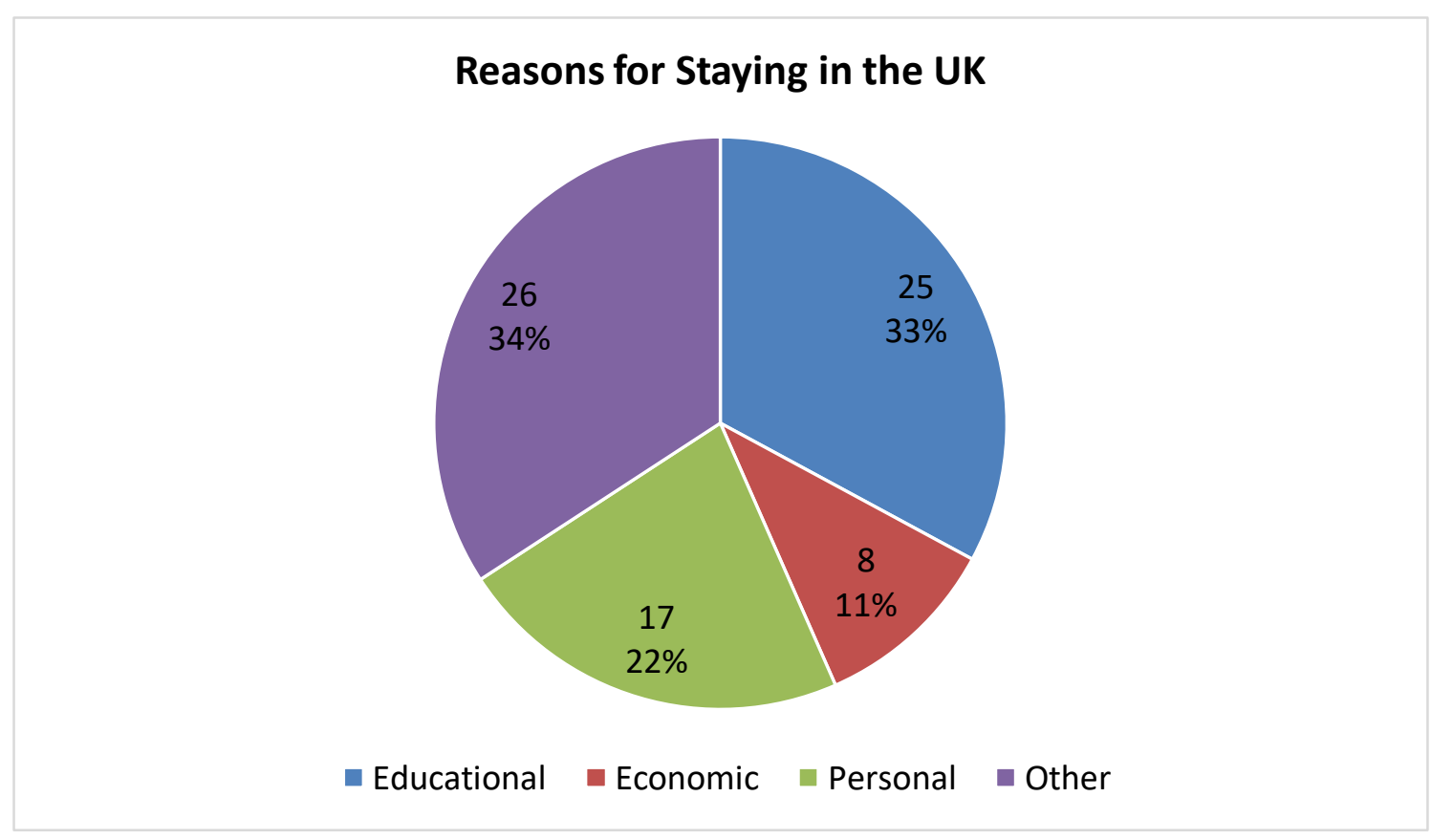

Figure 4. Reasons for Staying in the UK 


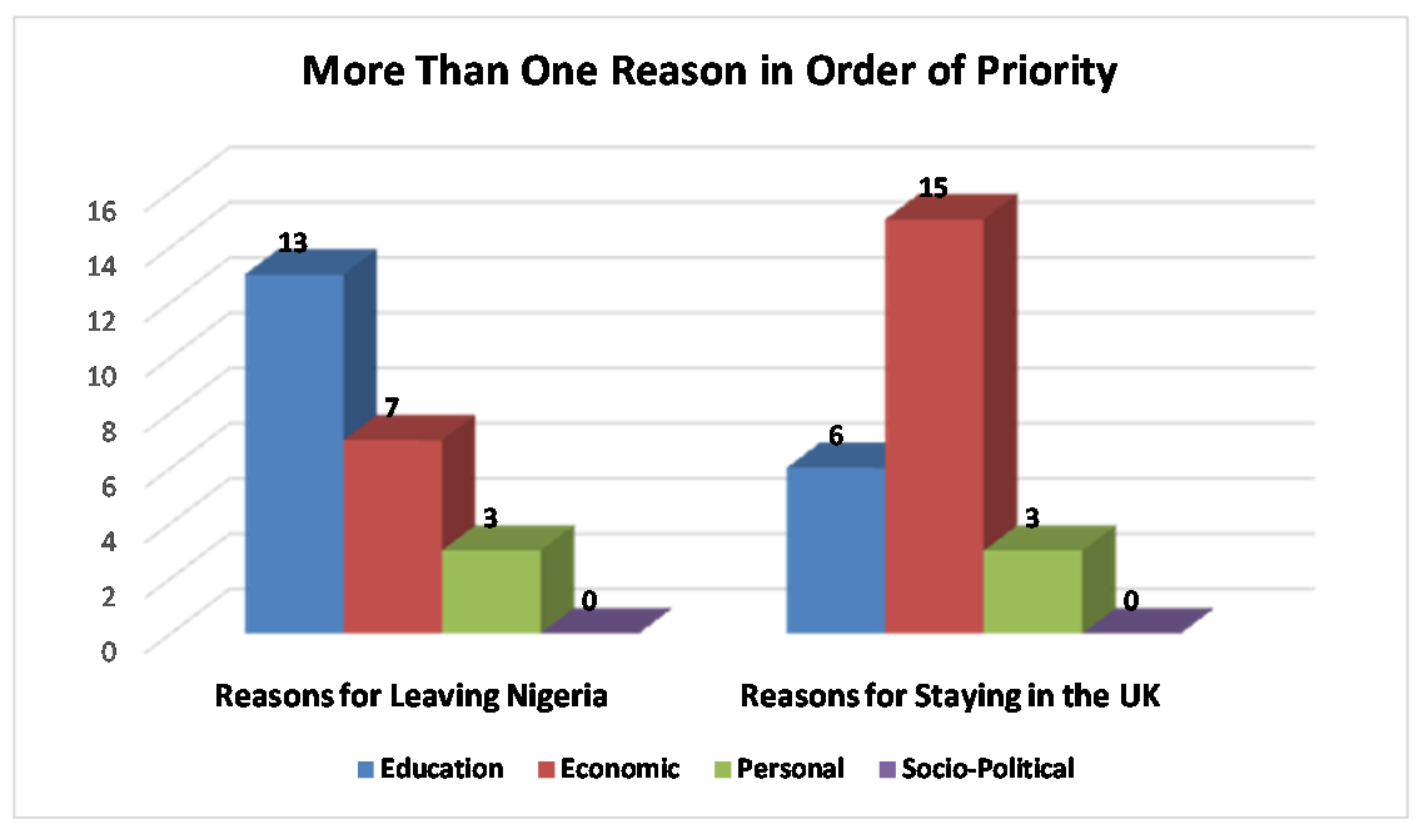

Figure 5. More than One Reason in Order of Priority

Using the Socio-cultural adjustment model of Black \& Stephens (1989), the survey also obtained information on the degree of adjustment of the participants socio-culturally. The relevant areas of the model as applicable to the context of this study and the analysis of the responses are shown in Figure 6.

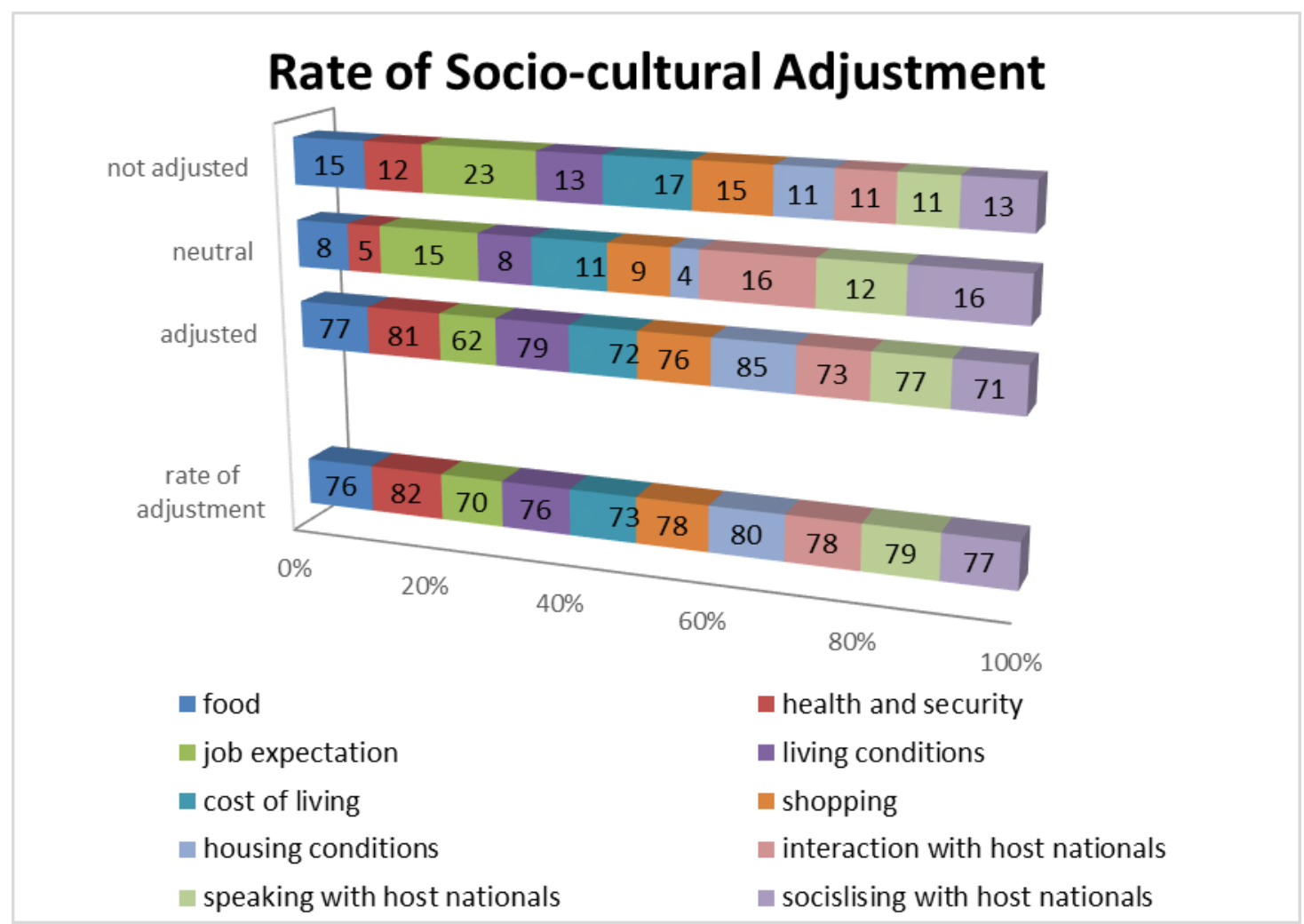

Figure 6. Rate of Scio-Cultural Adjustment 
On the issue of food, the result shows that $57(77 \%)$ of the respondents had conveniently adjusted, 6(8\%) remained neutral while $11(15 \%)$ indicated unadjusted. The average rate of the adjustment was 5.30 on the scale of $7 \mathbf{7 6 \%})$. In response to the health and security system, $58(81 \%)$ had adjusted, 5(7\%) were indifference and 9(11\%) were unadjusted. The average rate of adjustment on the scale of 7 , was $5.76(\mathbf{8 2} \%)$. The job expectation aspect had $45(62 \%)$ adjusted, 11(15\%) neutral and 17(23\%) unadjusted and the rate of adjustment was $4.92(\mathbf{7 0 \%})$. The rate of adjustment to the general living conditions was 5.34(76\%) with 57(79\%) adjusted, $6(8 \%)$ neutral and $10(13 \%)$ unadjusted. 54(72\%) had adjusted to the cost of living but $13(17 \%)$ were unadjusted while $8(11 \%)$ were neutral and the rate on the scale of 7 , was $5.09(73 \%)$. Looking at the result on the shopping system of the UK, 57(76\%) had adjusted and $11(15 \%)$ were unadjusted. The rate of adjustment was 5.45 on the scale of $7 \mathbf{( 7 8 \% )}$ because $7(9 \%)$ maintained neutral position. The housing conditions indicated $62(85 \%)$ as adjusted, 3(4\%) were indifferent and $8(11 \%)$ were unadjusted. The adjustment rate shows $5.60(80 \%)$. Interaction with the host nationals recorded $5.46(\mathbf{7 8 \%})$ as the rate of adjustment. $54(73 \%), 12(16 \%)$ and $8(11 \%)$ were adjusted, neutral and unadjusted respectively. Responses to the aspect of speaking with the host nationals, produced adjustment rate of 5.55 on the scale of $7(\mathbf{7 9 \%})$. The situation indicated that $58(77 \%)$ had adjusted but $8(11 \%)$ remained unadjusted and 9(12\%) were neutral. The rate at which the respondents had adjusted in socializing with the host nationals was $5.36(\mathbf{7 7 \%})$ because $53(71 \%)$ of them had adjusted and $12(16 \%)$ maintained neutrality but the remaining $10(13 \%)$ were adjusted.

\subsection{Analysis of the In-depth Interviews}

The demographics of the interviewees are indicated in Table 2 and their responses are analysed under the different themes below:

Table 2. Demographics of the Interviewees

\begin{tabular}{|c|c|c|c|c|c|c|}
\hline \multirow{2}{*}{$\begin{array}{l}\text { DEMOGRAPHIC } \\
\text { QUESTIONS }\end{array}$} & \multicolumn{6}{|c|}{ INTERVIWEES AND THEIR RESPONSES } \\
\hline & T.T. & Soma X. & Dee & Bum & Teed & Hoppy \\
\hline Gender & Male & Male & Female & Female & Female & Female \\
\hline Age & $30-39$ & 38 & 32 & 28 & 34 & 23 \\
\hline Religion & Christian & Christian & Christian & Christian & Christian & Christian \\
\hline $\begin{array}{l}\text { Type of } \\
\text { Occupation }\end{array}$ & F/T Employment & Self-employment & F/T Student & F/T Employment & F/T Employment & $\mathrm{F} / \mathrm{T}$ Student \\
\hline $\begin{array}{l}\text { Educational } \\
\text { Qualification }\end{array}$ & BSc & MSc & HND & BA & BSc & BSc \\
\hline Marital Status & Married & Married & Married & Married & Married & Single \\
\hline $\begin{array}{l}\text { Dependants in } \\
\text { Nigeria }\end{array}$ & 20 & 1 & Nil & Nil & 1 & Nil \\
\hline $\begin{array}{l}\text { Dependants in the } \\
\text { UK }\end{array}$ & Nil & 2 & 2 & 2 & Nil & Nil \\
\hline $\begin{array}{l}\text { Length of Stay in } \\
\text { the UK so far }\end{array}$ & 6 years & 12 years & 6 years & 12 years & $61 / 2$ years & $11 / 2$ years \\
\hline
\end{tabular}

While other themes of the research were discussed during the in-depth interviews, emphasis was placed on the theme of culture shock by job expectations of the SIEs. The interviewees were requested to describe their experiences in the area of job expectation in the UK and their responses showed that what they met were different from what they were expecting. The similarity in the educational systems of the two nations notwithstanding, employers in the UK 
always requested for the UK based work experience. Because of this, all the interviewees started jobs that were far below their expected type of jobs and educational qualifications.

T.T.: "You could be a graduate or even a manager of a bank (in Nigeria) ... can't even get a customer service job in a bank (in the UK). In spite of Nigerian being one of their former colonies, ... I would say almost $99.9 \%$ of the people (Nigerians) I know are not doing what they are qualified to do. Most of them ... have BSc ..... BSc studied in the United Kingdom and errr they still do that type of jobs. They (UK employers) always ask for their skill".

\subsubsection{Socio-Cultural Adjustment}

In order to investigate how adjusted the participants were, to the socio-cultural environment of the UK, appropriate questions were asked. The responses show that though they still felt homesick from time to time, they had adjusted pretty well but Dee insisted she had not really adjusted owing to her love for Nigeria where she was certain to return later. She said, "Errrrm, not really adjusted. Partially adjusted... As I said earlier, I am giving myself a time frame. My children are still kind of young so I am looking at 8 to 10 years from now and I will have to go back home. So, am encouraging myself to adapt to whatever am facing here for that period of time".

\subsubsection{Factors Influencing the Adjustment}

The factors that were instrumental to their adjustment could be seen in their responses as their family and friends; the intrinsic self determination to survive in the host nation; the deferred gratification; the drive to satisfy the original reasons for relocation, continuous interaction with the UK environment and the value of life generally in the UK.

Bum: "I have got used to it now. I have seen it as the normal way of life here so I have got used to it and accepted it. If you don't, then you go back".

Hoppy: "Yes I have fully adjusted. The experience in the part-time job that I got made it easy for me to adjust". She also pointed to the fact that appropriate pre-departure information could help in adjusting. "....this affected me too so I can advise anybody to get enough and correct information about the situation here before coming”.

Soma $X$., Dee and Bum had separately attained UK citizenship by marriage but while Soma $\boldsymbol{X}$. and Bum were seeing UK as 'home', Dee described it as 'second home' "...UK is my home I mean second home” with a strong interest in returning to Nigeria.

\subsubsection{Racial Discrimination}

On the issue of racial discrimination against the Nigerians in the UK, the interviewees severally submitted that though not well pronounced, there were some subtle manifestations of discrimination which was obvious in the type of jobs they could secure.

T.T.: "Here, there is a bit of racism."

Soma $X .:$ "...it is subtle in a way....errrr discrimination is subtle. I remember a gentleman telling me 'you know what? you earn pounds and not pebbles.. ...liking Naira (the Nigerian 
currency) to pebbles. 'And I felt insulted. I was really offended".

\section{Interpretation of Results}

The findings of the research are discussed by relating the data analysis with the existing theories and propositions in the area of the study and in response to the research questions and objectives.

\subsection{Factors that Influence Migration}

The findings from both approaches have identified that educational and economic factors are paramount (See Figures 3, 4 and 5). Many Nigerian SIEs left Nigeria in search of a better place to study or further their study which is invariably, expected to lead to better life standard (Baruch et al, 2007). Personal reasons which include family influence are also important factors that are 'pushing' Nigerians out of their nation of origin. The socio-political reasons as submitted by (Stilwell et al., 2004 and Healy \& Oikelome, 2007), are also confirmed by this research as factors that 'push' Nigerians into migration, but it is not as prominent as the other factors (Altman \& Baruch, 2013). The findings also revealed that many Nigerians originally came to the UK to study but eventually stayed for economic reasons after securing employment (Al-Ariss \& Özbilgin, 2010) (Soma X.: “...Primary reason was more or less educational reason which I believe it led to the secondary reason ...economic." See also Figure 5). The findings show clearly that most Nigerians have more than one reasons for leaving their home country according to the expanded 'push/pull' model of (Altman \& Baruch, 2013; See Figure 2). The influence of family can be included in an emigrant's educational or economic reasons to relocate (Kasinitz et al., 2009, Foner \& Alba, 2010 and Imoagene, 2012). The information from family and friends about the prospects that UK holds for them, are paramount among the reasons for choosing the UK as a destination (Bum: "It was mainly...errr I migrated with the whole family, to study but for my parents, it was to work").

\subsection{Forms of Culture Shock Experience}

The findings show tremendously, that the Nigerians really experience culture shock in the UK. Briscoe et al., (2012) had submitted that it is quite certain that any exposure to a new socio-cultural environment will provoke some culture shock, notwithstanding the person's broadmindedness. The findings of this research uphold this stance because all the respondents submitted that they experienced culture shock in the UK. The findings also show that the Nigerian SIEs experience culture shock in all the areas suggested in the questionnaires and the interviews also confirmed culture shock with additional information. (Soma X.: "...You don't really know your next door neighbour... The food was so strange”. Hoppy: "...the living expenses. It is quite high. The mode of dressing.... Sometimes, you cannot even tell who is a boy from who is a girl").

One prominent form of culture shock as the gathered information has revealed, is in the area of job expectation. The findings confirmed the argument of Vujicic et al., (2004), Healy \& Oikelome, (2007) and Imoagene (2012), that the enthusiasm with which Nigerian skilled migrants come to the UK, in terms of the job expectation, are not met most of the time. The 
similarity in the educational systems of the two nations does not translate to commensurate qualification-employment placement. Most Nigerians in the UK started out with odd and menial jobs to survive because their educational qualifications are secondary to their acquisition of the UK based work experience. It is a fact that the system of education in Nigeria is a product of the decades of the British colonial rule of the nation. Nigerians who are products of the system are taken aback when they discovered that their educational qualifications are not reckoned with in the UK, as expected. This discrimination in the argument of Healy and Oikelome (2007), was a great shock to the Nigerians in the UK. Imoagene (2012) also argued that the situation could affect the self-esteem and value of the migrants in the UK which could result to vengeful social behaviour. T.T.: “... Considering that Nigeria and the UK have a similar system of education and being one of their former colonies, we have a lot of similarities in our business formation. We have a lot of British companies in Nigeria but getting here you can't even get such job you expect by your qualifications. That was a great shock!"

Closely linked with the non-recognition of the Nigerian's educational qualification, is the question of racial discrimination and the findings show that despite the official rule against racial intolerance in the UK, there are still some subtle forms of it. This manifests in forms of career glass-ceiling, house rent and verbal attacks. Even Nigerians who have attained British citizenship, still experience discrimination because of their colour (Foner \& Alba, 2010). The racial discrimination is actually killing the potentials of the Nigerian migrants in the UK. The information provided by the interviewees revealed that their inability to provide UK-based work experience was responsible for the employers' refusal to employ them on the pedestal of their qualification and skill (Noon, 1993).

Soma X.: “...applying for job, job expectation, asking for UK experience when your experience in Nigeria is not recognised."

A thorough look at the situation along the status of the respondents, revealed that the discrimination is actually against the race and not the qualification because even the educational qualification obtained within the UK could still not afford the Nigerians, access to real professional career in the UK. T.T. Dee and Bum: "I would say almost $99.9 \%$ of the people I know are not doing what they are qualified to do. Most of them are currently doing what you would expect somebody with an NVQ to be doing and some have BSc ..... BSC studied in the United Kingdom and they still do that type of jobs".

\subsection{Factors Influencing the SIEs' Continuous Stay in the UK}

The findings of this study also reveal the factors that keep the Nigerian SIEs going in the UK, in spite of the various forms of culture shock they experience. The factors include the influence of family (mostly direct dependants) and friends. The strong and tenacious nature of Nigerians to survive in the host nation; and the deferred gratification (Bum: "...Work harder and get a bigger house or build your own or you go back home...”). Some are encouraged to remain in the UK because the original reasons for relocation have not really improved (Healy \& Oikelome, 2007). Many Nigerians are ready to weather the storm in the UK for the sake of their family whose access to standard education and life, depend on their 
continuous stay in the UK. (Dee: "My children are still kind of young so ... I am encouraging myself to adapt to whatever am facing here for that period of time"). The fact that one can still achieve his/her economic aspiration, is another factor that keeps the Nigerian SIEs in the UK (Vujicic et al., 2004). The researcher also found in his reflexive involvement in the study, that most of the respondents encouraged themselves to overlook the issue of racial discrimination because they were still able to achieve economic aspiration.

This situation is actually depriving them of their original career ambitions. The likes of the respondents in this study may never be found in management positions in the UK meanwhile they have better qualifications than their British counterparts in such positions. The obtained data revealed that the respondents accepted to do odd and menial jobs in the UK rather than returning to Nigeria because the seemingly meagre earnings in the Great Britain Pounds are translating to huge amount of Nigerian Naira. This revelation substantiates the argument of Saxenian (2007) and Iredale et al. (2003) that many African migrants are of great economic benefits to their relations back home. The international remittance report according to Olumide and Wilfred (2012), reveals that the officially registered remittances to developing and former communist countries in 1999 , was over $\$ 65$ billion and $\$ 80$ billion in 2002. The report further stated that the total of officially transferred remittances was $40 \%$ higher than all official development aid such developing region Olumide and Wilfred (2012). To make this financial remittance possible, the respondents in this study were ready to trade their career ambition for economic aspiration. This strange resolution of the respondents to sacrifice their self-esteem and career aspiration on the platter of economic gain, is another important findings of this study.

Additional information from the in-depth interviews reveals that access to adequate pre-departure information and intrinsic preparedness to adopt to the host nation's environment, are among the factors that keep the Nigerian SIEs going in the UK (Hoppy: "....this affected me too so I can advise anybody to get enough and correct information about the situation here before coming").

\subsection{Socio-Cultural Adjustment}

The findings further reveal that the Nigerian SIEs in the UK are pretty well adjusted to the host nation's environment. The result of testing the socio-cultural adjustment model of Selmer, (2001), in this study reveals that on the scale of 7, the rate of adjustment is between 5.30 and 5.76 in all the forms of the culture shock except in the job expectation which is 4.92 . Though this rate on job expectation, is lower than others, it still shows that the SIEs are adjusted. It is evidence however, that many Nigerian SIEs in the UK would prefer a situation where their professional and career aspirations could be achieved (Saxenian, 2007). The inclusion of other findings from the in-depth interview in this study, in such graph plotting will also confirm the ' $\mathrm{S}$ ' shape graph argued by Bhaskar-Shrinivas et al., (2005). This is because some of the interviewees still feel homesick from time to time.

\section{Conclusion and Recommendations}

From the findings, the following discoveries were made: 


\section{$\Lambda$ Macrothink}

Factors like educational, economic, personal and socio-political were responsible for the incessant migration of the Nigerians to the UK. Some Nigerian SIEs migrated mainly because of any one of these factors while some responded to a combination of the factors, to migrate (Altman \& Baruch, 2013). Apart from the educational, economic and personal factors tested by the survey, findings from the in-depth interview revealed that a combination of these factors and family influence also determine the foreign destination of the migrants. The findings also revealed that the Nigerian SIEs experienced culture shock in virtually, every sphere of their interaction with the host nationals and the environment. The food types and system, the social interaction system, dressing, weather, types of job/job expectation, housing system, shopping system, health and security facilities and many more were shocking to the participants (Selmer, 2001). The social and legal stance of the host nation on some matters like marriage and human right, were found strange by some of the participants too. Some factors were also revealed by the findings as the reasons behind the Nigerian SIEs' resilient ways of continuing their stay in the UK in spite of the culture shock experiences. The 'pulling' factors mentioned in (Altman \& Baruch, 2013)'s expanded 'push/pull' model were revealed as very paramount in keeping them in the UK. The fact also emerged that the original 'push' factors back home in Nigeria are continuously 'pushing' the SIEs (Vujicic et al., 2004).

Finally, the findings revealed that the SIEs adjust well both socio-culturally and psychologically, to the host nation's environment. However, the submission of (Saxenian, 2007), that some SIEs regularly trip to their home countries, was confirmed by the findings of this study. It was also revealed that against the straight jacketed adjustment stages of Oberg (1960), culture shock is a continuous occurrence as long as the SIE remains in the foreign nation (Black \& Stephen, 1989).

Some existing theories and propositions have been affirmed by the findings of this study while some were contradicted. The factors that influence the migration of Organisational Expatriates (OEs) and even the SIEs within the multinational companies may not necessarily influence the types of SIEs in the context of this study. This research has therefore successfully broadened the academic spectrum in the fields of self-initiated expatriates, international labour mobility and migration generally. This study, through its findings, is arguably revealing some managerial and academic implications now that there are calls for a proper utilisation of the SIEs on MNCs' foreign assignments. Therefore, it is recommended that, in the scheme of further study on the utilisation of SIEs on foreign assignments, adequate attempt should be made to integrate this particular type of SIEs, in the context of this study. Having proved that they can survive the diverse cultures, multinational companies' managers should also begin to harness the SIEs in this study, on foreign assignment both at their home and host nations. National governments and international bodies should endeavour to minimise if not totally eradicate, racial discrimination across the globe.

\section{Note}

In order to protect the anonymity of the interviewees, aliases are used rather than real names. 


\section{Reference}

Al Ariss, A. A. (2010). Modes of engagement: Migration, self-initiated expatriation, and career development. Career Development International, 15(4), 338-358. http://dx.doi.org/10.1108/13620431011066231.

Al Ariss, A., \& Özbilgin, M. (2010). Understanding self-initiated expatriates: Career experiences of Lebanese self-initiated expatriates in France. Thunderbird International Business Review, 52(4), 275-285. https://doi.org/10.1002/tie.20355

Altman, Y., \& Baruch, Y. (2013). Global self-initiated corporate careerists: what drives them and implications for HRM. In A. Haslberger, \& V. Vaiman, (Eds.), Talent Management of Self-Initiated Expatriates: A Neglected Source of Global Talent, pp. 19-29). London: Palgrave MacMillan. https://doi.org/10.1057/9780230392809_2

Baruch, Y., Budhwar, P. S., \& Khatri, N. (2007). Brain drain: Inclination to stay abroad after studies. Journal of World Business, 42(1), 99-112. https://doi.org/10.1016/j.jwb.2006.11.004

Berry, J. W. (1997). Immigration, acculturation, and adaptation'. Applied Psychology, 46(1), 5-34. https://doi.org/10.1111/j.1464-0597.1997.tb01087.x

Bhaskar-Shrinivas, P., Harrison, D. A., Shaffer, M. A., \& Luk, D. M. (2005). Input-based and time-based models of international adjustment: Meta-analytic evidence and theoretical extensions. Academy of Management Journal, 48(2), 257-281. https://doi.org/10.5465/amj.2005.16928400

Black, J. S., \& Stephens, G. K. (1989). The influence of the spouse on American expatriate adjustment and intent to stay in Pacific Rim overseas assignments. Journal of Management, 15(4), 529-544. https://doi.org/10.1177/014920638901500403

Briscoe, D. R., Shuler, R. S., \& Tarique, I. (2012). International Human Resource Management. (4th ed.). London: Routledge. https://doi.org/10.4324/9780203816189

De Haas, H. (2005). International migration, remittances and development: Myths and facts. Third World Quarterly, 26(8), 1269-1284. https://doi.org/10.1080/01436590500336757

Edwards, T., \& Rees, C. (2011). International Human Resource Management. (2nd ed.). London: FT Prentice Hall.

Foner, N., \& Alba, R. (2010). Immigration and the legacies of the past: the impact of slavery and the holocaust on contemporary immigrants in the United States and Western Europe. Comparative Studies in Society and History, 52(4), 798-819. https://doi.org/10.1017/S0010417510000447

Harzing, A-W., \& Pinnington, A. H. (2011). International Human Resource Management. (3rd ed.). London: Sage.

Haslberger, A. (2008). Expatriate adjustment. International Human Resource Management: A European Perspective, (21), 130-147. https://doi.org/10.4324/9780203891391.ch7 
Healy, G., \& Oikelome, F. (2007). Equality and diversity actors: a challenge to traditional industrial relations? Equal Opportunities International, 26(1), 44-65. https://doi.org/10.1108/02610150710726525

Imoagene, O. (2012). Being British vs being American: identification among second-generation adults of Nigerian descent in the US and UK. Ethnic and Racial Studies, 35(12), 2153-2173. https://doi.org/10.1080/01419870.2011.631556

Iredale, R. R., Guo, F., \& Rozario, S. (2003). Return Migration in the Asia Pacific, Edward Elgar Publishing.

Jaime B. (2005). Job satisfaction among expatriates, repatriates and domestic employees: The perceived impact of international assignments on work-related variables. Personnel Review, 34(1), 110-124. https://doi.org/10.1108/00483480510571905

Kasinitz, P., Mollenkopf, J. H., Waters, M. C., \& Holdaway, J. (2009). Inheriting the City: The Children of Immigrants Come of Age. Russell Sage Foundation.

Kingston, E., \& Forland, H. (2008). Bridging the gap in expectations between international students and academic staff. Journal of Studies in International Education, 12(2), 204-221. https://doi.org/10.1177/1028315307307654

Marecek, J., Fine, M., \& Kidder, L. (1997). Working between worlds: qualitative methods and social psychology', Journal of Social Issues, 53(4), 631-645. https://doi.org/10.1111/j.1540-4560.1997.tb02452.x

Nankervis, A., Compton, R., \& McCarthy, T. (1993). Strategic Human Resource Management, Thomas Nelson Australia, South Melbourne.

Noon, M. (1993). Racial discrimination in speculative application: Evidence from the UK's top 100 firms. Human Resource Management Journal, 3(4), 35-47. https://doi.org/10.1111/j.1748-8583.1993.tb00321.x

Oberg, K. (2006). Cultural shock: adjustment to new cultural environments, Curare, 29(2), 43-146.

OECD. (2013). International Migration Outlook, Paris: OECD. https://doi.org/10.1787/migr_outlook-2013-en

Olumide H. B., \& Wilfred. I. U. (2012). Brain drain and African development: Any possible gain from the drain? African Journal of Business Management, 6(7), 2421-2428. doi: 10.5897/AJBM11.2385.

Saxenian, A. (2007). The New Argonauts: Regional Advantage in a Global Economy. Harvard University Press.

Schütter, H., \& Boerner, S. (2013). Illuminating the work-family interface on international assignments: An exploratory approach. Journal of Global Mobility: The Home of Expatriate Management Research, 1(1), 46-71. https://doi.org/10.1108/JGM-09-2012-0012 


\section{Macrothink}

International Journal of Human Resource Studies

ISSN 2162-3058 2019, Vol. 9, No. 1

Selmer, J. (2001). Expatriate selection: back to basics? International Journal of Human Resource Management, 12(8), 1219-1233. https://doi.org/10.1080/09585190110083767

Stilwell, B., Diallo, K., Zurn, P., Vujicic, M., Adams, O., \& Dal Poz, M. (2004). Migration of health-care workers from developing countries: strategic approaches to its management. Bulletin of the World Health Organization, 82(8), 595-600.

Stroh, L. K., Gregersen, H. B., \& Black, J. S. (1998). Closing the gap: expectations versus reality among repatriates. Journal of World Business, 33(2), 111-124. https://doi.org/10.1016/S1090-9516(98)90001-3

Vujicic, M., Zurn, P., Diallo, K., Adams, O., \& Dal Poz, M. R. (2004). The role of wages in the migration of health care professionals from developing countries. Human Resources for Health, 2(1), 3-12. https://doi.org/10.1186/1478-4491-2-3

Ward, C. \& Kennedy, A. (1992). Locus of control, mood disturbance and social difficulty during cross-cultural transitions. International Journal of Intercultural Relations, 16, 175 -194. https://doi.org/10.1016/0147-1767(92)90017-O

Welch, D. E., Welch, L. S., \&Worm, V. (2007). The international business traveller: a neglected but strategic human resource. The International Journal of Human Resource Management, 18(2), 173-183. https://doi.org/10.1080/09585190601102299

\section{Copyright Disclaimer}

Copyright for this article is retained by the author(s), with first publication rights granted to the journal.

This is an open-access article distributed under the terms and conditions of the Creative Commons Attribution license (http://creativecommons.org/licenses/by/4.0/). 